\title{
Alternative phase transformation path in cryogenically treated AISI D2 tool steel
}

\author{
Hadi Ghasemi Nanesa ${ }^{1}$, Mohammad Jahazi \\ Department of Mechanical Engineering, École de Technologie Supérieure, 1100 rue Notre-Dame Ouest, \\ Montréal (QC) H3C 1K3 Canada.
}

\begin{abstract}
This study based on dilatometry test and microstructural observations showed a different phase transformation path during conventional heat treatment of AISI D2 tool steel instead of the traditionally expected fully martensitic transformation. Transformation started with carbide precipitation and continued with allotriomorphic ferrite, Widmanstätten ferrite, acicular ferrite, and finally bainite formation. This microstructure showed microhardness value of $730 \mathrm{HV}$, which is very high for conventionally cooled samples. They are not expected to have gone under martensitic transformation. The results indicated that bainitic transformation take place even at temperatures near $173 \mathrm{~K}$ and to obtain fully martensitic microstructure, cooling rates in the range of $50 \mathrm{~K} . \mathrm{s}^{-1}$ must be utilized.
\end{abstract}

\section{Keywords}

A. Electron microscopy, A. Hardness measurements, B. Steel, D. Phase transformation.

\section{Introduction}

AISI D2 tool steel is widely used in mold making industry and as high speed cutting tools, where ultra-high strength with high wear resistance and good toughness is required [1-3]. Conventional heat treatment consisting of austenitizing + cooling to room temperature + tempering is the principal process used for this alloy. The microstructure of conventionally heat treated alloy $(\mathrm{CHT})$ is composed of laths of martensite, a variety of

1 Corresponding author. Tel.: + 514396 8974; fax: 514396 8530. E-mail address: hadi.ghasemi-nanesa.1@ ens.etsmtl.ca. 
carbides, and some retained austenite [1-3]. After CHT, AISI D2 tool steel shows ultrahigh strength and excellent wear resistance; however it suffers from low toughness in service [4]. The decomposition of retained austenite to ferrite and cementite during tempering process ( $\approx 773 \mathrm{~K}$ has been related to the loss of toughness of this alloy [4]. It is also generally accepted that martensite start and finish temperatures for AISI D2 steel are at subzero temperatures $[5,6]$ and in order to reduce the amount of retained austenite, an additional step, cryogenic cooling, has been used to insure attaining martensite finish temperature and therefore to obtain the maximum volume fraction of martensite [4]. Most of the research studies on AISI D2 tool steel have been conducted on the microstructure after tempering and little attention has been paid to the microstructure of the as-hardened alloy [4-7]. Moreover, in all the above studies the microstructure before tempering is considered as fully martensitic with very little or no metallographic supports. In the present study, dilatometry tests combined with detailed microstructure observations was carried out and revealed that the microstructure of as hardened (i.e. prior to tempering) AISI D2 steel is composed of mainly bainite (B) with partial carbide precipitation (CP), allotriomorphic ferrite (ATF), Widmanstätten ferrite (WF), and acicular ferrite (AF) formation. This finding can open a new chapter in hardening process of this alloy and bring many possibilities for microstructure engineering.

B ÄHR DIL 805 A/D dilatometer with a $50 \mathrm{~nm}$ resolution at high speed cooling rates was used to carry out the hardening treatment. $0.5 \mathrm{~K} \cdot \mathrm{s}^{-1}$ and $50 \mathrm{~K} \cdot \mathrm{s}^{-1}$ were specifically used in this study. The first cooling rate was selected in order to simulate cooling rates employed in conventional hardening heat treatment and the second one was selected fast enough to insure the occurrence of martensitic transformation. The critical cooling rate to get full 
martensitic microstructure without carbide precipitation during cooling has been reported to be about $10 \mathrm{~K} \cdot \mathrm{s}^{-1}$ [8]. In order to pass both martensite start and finish temperatures and also to follow transformations at sub-zero temperatures, the final cooling temperature was selected to be $173 \mathrm{~K}$.

\section{Material and methods}

The as-received AISI D2 sheet's chemical composition was of (wt pct) C 1.54 - Si 0.33 Mn 0.32 - Cr 11.88- Mo 0.76 - V 0.75- P 0.008- S 0.008. Samples were cut into $10 \mathrm{~mm}$ height and $4 \mathrm{~mm}$ diameter cylinders. They were then heated to $1303 \mathrm{~K}$ and maintained for 1200 seconds ( 20 minutes) following by continuous cooling to $173 \mathrm{~K}$ with the two above mentioned rates. Finally, they were reheated to room temperature at heating rate of $10 \mathrm{~K} . \mathrm{s}^{-1}$. In order to avoid any oxidation and decarburization, the heat treatment was conducted in vacuum environment. Microstructural studies were conducted using NADE NMM-800TRF optical microscope (OM) and Hitachi-TM3030 scanning electron microscope (SEM), and an FEI Tecnai G2 F20 transmission electron microscope (TEM) operated at $200 \mathrm{kV}$. An etchant with the following composition $40 \mathrm{~g} \mathrm{NaOH}+60 \mathrm{~g} \mathrm{H}_{2} \mathrm{O}+15 \mathrm{~g} \mathrm{NaNO}_{3}$ initially proposed by Gouné et al.[9] was modified and successfully used to differentiate bainite (bright) from non-tempered martensite (dark) and to reveal prior austenite grain boundaries (PAGBs). Dilatometry results with their first derivative diagrams were analyzed to study the different phase transformations taking place during cooling. Hardness of the matrix was estimated using Vickers method using an applied load of $200 \mathrm{gf}$ for 15 s. Special care was taken during hardness measurements to avoid large carbides. The volume fraction of carbides were calculated using S3600N (Hitachi) conventional SEM and the MIP® image analysis software [10]. 


\section{Results and discussion}

Figure 1a-d shows the microstructure of the sample cooled at $0.5 \mathrm{~K}_{\mathrm{s}}{ }^{-1}$. In this figure, part (a) displays OM image of the microstructure with the bright area representing bainite and the dark area PAGBs. WF (indicated by the arrow Figure 1b) was found at PAGBs or developed from any ATF present in the microstructure (indicated by the arrow in Figure 1c) [11]. On the other hand, as shown in Figure 1d; AF grows directly from the interface of carbides with austenite. Figure 1e and 1f show OM and SEM images of the fully martensitic microstructure obtained after a cooling rate of $50 \mathrm{~K} . \mathrm{s}^{-1}$. No evidence of ATF, $\mathrm{WF}, \mathrm{AF}$, and $\mathrm{B}$ and no elemental concentration gradient at grain boundaries were found in this sample, indicating similar chemical composition with the parent austenite. Figures $2 \mathrm{a}-\mathrm{b}$ show TEM micrographs representing bainitic plates including smaller sub-units while Figures 2c-d depict mixed morphology of laths and plates for martensite.

Phase transformations and their related slope changes with associated first derivative curve for the two investigated cooling rates are shown in Figures 3 and 4. At 0.5 K.s ${ }^{-1}$ cooling rate (Figure 3a), four distinct regions were determined depending on the transformation temperatures and slope changes on dilatometry diagrams. Region (1) is associated with carbide precipitation (CP). Region (2) is related to the temperature interval for ATF and WF formation [12]. Region (3) is associated with AF formation range and region (4) corresponds to bainitic transformation. The small drop observed around $300 \mathrm{~K}$ is due to the introduction of liquid nitrogen in the system in order to cool the sample down to 173K. Detailed examination of the first derivative curve of the dilatometry data for region

(3) (Figure 3b) showed slight deviation from linear behavior between $580 \mathrm{~K}$ and $510 \mathrm{~K}$ and 
is ascribed to $\mathrm{AF}$ start and finish temperatures. Using first derivative curve, the bainite start temperature $\left(\mathrm{B}_{\mathrm{s}}(\mathrm{T})\right)$ was measured to be $480 \mathrm{~K}$. At $50 \mathrm{~K} \cdot \mathrm{s}^{-1}$ cooling rate, no trace of regions 1,2, 3 and 4 was discerned.

However, splitting phenomenon [13] for martensitic transformation was detected as shown by dashed circle in Figures 4a-b. Here again, for higher accuracy purposes, martensite start temperatures $\left(\mathrm{M}_{\mathrm{s} 1,2}(\mathrm{~T})\right)$ were measured using first derivative curve. The value of $\mathrm{M}_{\mathrm{s} 1}(\mathrm{~T})$ was determined to be around $490 \mathrm{~K}$ while for $\mathrm{M}_{\mathrm{s} 2}(\mathrm{~T})$ it was found to be around $450 \mathrm{~K}$. The sudden change in cooling rate drop observed around $300 \mathrm{~K}$ is also due to the introduction of liquid nitrogen in the system.

Hardness measurements of the sample quenched at $0.5 \mathrm{~K} . \mathrm{s}^{-1}$ was indicated a value of $730 \pm 15 \mathrm{HV}$ while this value was $910 \pm 55 \mathrm{HV}$ for the fully martensitic microstructure. It is interesting to note $730 \mathrm{HV}$ is very high for conventionally cooled samples without any martensitic transformation. To better understand this behavior, more in depth microstructural examination was carried out. Initially, the size and volume fraction of carbides were obtained from image analysis of the unetched microstructure with a method used in reference 14. In fact, etching could cause higher volume fraction measurement due to the bigger perceptible area for carbides and lower amount for smaller carbides (as they may be washed out during the etching process). Figures $5 \mathrm{a}$ and $\mathrm{b}$ show the image analysis results related to the size and volume fraction of carbides after (a) $0.5 \mathrm{~K} . \mathrm{s}^{-1}$ and (b) $50 \mathrm{~K} . \mathrm{s}^{-1}$ cooling rates, respectively.

As illustrated, higher volume fraction of carbides with surface area below $1 \mu \mathrm{m}^{2}$ is obtained for the sample cooled with conventional rate but no major differences were found for larger carbides. The above findings confirm that the observed change in dilatometry 
curve for this sample (region 1 in Figure 3a) correspond to carbide precipitation. The

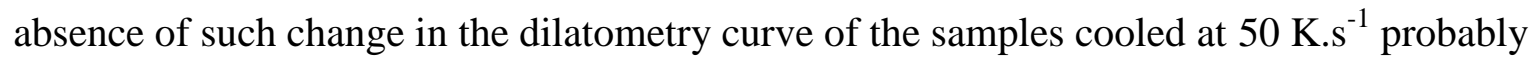
prevents redistribution of carbon atoms during cooling and does not allow for their clustering and eventually formation of carbides. As a result, no change is observed in the slope of the dilatometry curve (Figure $4 a-b)$.

For conventionally cooled sample, the first phase transformation, when cooling from the austenitizing temperature of $1300 \mathrm{~K}$ down to around $960 \mathrm{~K}$, corresponds to the precipitation of $\mathrm{M}_{7} \mathrm{C}_{3}$ carbides. Thermocalc studies by Bombac et al. [15] have shown that this range corresponds to carbides formation only. Further cooling to eutectoid temperature initiates the formation of a small amount of ATF at grain boundaries as a result of austenite decomposition by diffusion controlled processes [16-18]. It has been reported that the interface between the newly formed ATF and austenite can be inert or active and that WF and B can form only at the interface when the latter is active [19]. Therefore, the presence of WF and B at the interface of the ATF and austenite boundary found in the present investigation confirms that the boundary is active [18]. It must be noted that, WF forms at higher temperatures compared to B [12]. The analysis of the AF characteristics revealed that this phase nucleates mostly on $\mathrm{M}_{7} \mathrm{C}_{3}$ and $\mathrm{M}_{23} \mathrm{C}_{6}$ carbides. These two carbides are the most ones present in AISI D2 steel (Figure 1d) [20, 21].

Finally, after partial formation of acicular ferrite, the remained austenite undergoes bainitic transformation. No sign of double deviation from linear behavior [13] that would show the activation of martensitic transformation after bainitic transformation was found in dilatometry diagram of conventionally cooled sample. Therefore the transformation path for AISI D2 steel is more of bainitic type with carbide precipitation instead of a fully 
martensitic structure. It must be noted that AF has more importance than B as it directly contributes to the toughness and strength of the alloy. As a result, the formation of AF on carbides must be taken into consideration during heat treating of AISI D2 steel. As indicated by dilatometry results (Figure 3a), decreasing the temperature down to $173 \mathrm{~K}$ showed that the bainitic transformation still goes on. Thus cooling until room temperature is not enough to obtain martensitic or fully bainitic microstructures and retained austenite will be present in the microstructure after cooling. This austenite can decompose to ferrite and cementite during subsequent high temperature tempering and cause embrittleness.

\section{Conclusions}

Dilatometry results coupled with microstructural investigations showed an alternative phase transformation path during conventional heat treatment of AISI D2 tool steel. Instead of traditionally believed martensitic transformation, the obtained microstructure was composed of higher volume fraction of carbides with area below $1 \mathrm{~m}^{2}$, allotriomorphic ferrite, Widmanstätten ferrite, acicular ferrite, and mostly bainite. Also, it was found that for the investigated D2 steel cooling to room temperature is not enough to obtain fully martensitic or bainitic microstructures and retained austenite will be present in the microstructure after cooling.

\section{Acknowledgements}

The authors would like to thank the National Sciences and Engineering Research Council of Canada (NSERC) for their support and financial contribution through the ENGAGE and ENGAGE plus programs. The authors also appreciate the collaboration of DK SPEC Inc. for providing experimental materials, support from CanmetMATERIALS in the framework 
of RIEM program for dilatometry experiments, Hitachi Canada for privileged access to advanced microscopy facilities.

\section{References}

[1] A. P. Gulyaev, Metallurgy.12 (1937) 65-70.

[2] K. E. Thelning, Steels and its Heat Treatment, Butterworth \& Co Publishers Ltd, London, 1975.

[3] Tohru Arai, Gordon M. Baker, Charles E. Bates, Bruce A. Becherer, Tom Bell, Eugene L. Bird, Bruce L. Bramfitt, Robert L. Brennan, Charlie R. Brooks, Terrence D. Brown, Domenic A. Canonico, Earl A. Carlson, Arthur Cohen, James M. Dahl, Daniel A. DeAntonio, A.J. DeArdo, Douglas V. Doane, Jon L. Dossett, Joseph Douthett, David Duhl, Torsten Ericsson, Howard A. Ferguson, James H. Filkowski, Robert W. Foreman, B. Furchheim, C.I. Garcia, M. Gergely, Roger Gilbert, Arthur D. Godding, Dan Goodman, William L. Grube, Richard B. Gundlach, William B. Hampshire, Steven Harper, Peter A. Hassell, J.R. Hensley, Anil K. Hingwe, Mandar K. Hingwe, Timothy Howson, Lyle R. Jenkins, Paul Johnson, John R. Keough, John S. Kirkaldy, Christopher M. Klaren, Conrad H. Knerr, T. Konkoly, Bela Kovacs, George Krauss, George Y. Lai, W. James Laird, Jr., Steve Lampman, Gerard M. Ludtka, James M. Manning, Daniel W. McCurdy, James Nelson, James M. O'Brien, Raymond Ostrowski, E.J. Palmiere, S. Panzer, Roger Pradhan, T. Réti, Al Robertson, Kurt Rohrbach, Thomas C. Rose, Nicholas V. Ross, Michael F. Rothman, John G. Rowe, Thomas Ruglic, Karl B. Rundman, Larry Ryan, Robert F. Sagon-King, Jeremy St. Pierre,

Ole A. Sandven, S. Schiller, Michael Schmidt, C. Richard Shannon, John A. Shields, Jr., Anil Kumar Sinha, Gaylord Smith, John W. Smith, S. Somogyi, Archie Stevenson, C.A. Stickels, Albert S. Tenney III, Donald J. Tillack, George E. Totten, Steven Verhoff, Charles F. Walton, Herbert Webster, Michael W. Wisti, Thomas J. Witheford, ASM Handbook, Heat Treating, ASM International, USA, 1991.

[4] S. G. Singh, J. Singh, R. Singh, H. Singh, J. Adv. Manuf. Technol. 54 (2011) 59-82. 
[5] V. G. Gavriljuk, W. Theisen, V. V. Sirosh, E. V. Polshin, A. Kortmann, G. S. Mogilny, N. Petrov, Y. V. Tarusin, Acta Mater. 61 (2013) 1705-1715.

[6] E. A. Huallpa, J. C. Sánchez, L. R. Padovese, H. Goldenstein, J. Alloy. Compd. 577 (2013) S726-S730.

[7] D. Das, A. K. Dutta, K. K. Ray, Mater. Sci. Eng. A.527 (2010) 2182-2193.

[8] http://www.metalravne.com/selector/steels/OCR12VM.html

[9] M. Gouné, O. Bouaziz, S. Allain, K. Zhu, M. Takahashi, Mater. Lett. 67-1 (2012) 187-189.

[10] Nahamin Pardazan Asia, http://en.metsofts.ir/, Iran, 2014.

[11] D. E. Laughlin, K. Hono, Physical Metallurgy, 5th ed., Elsevier, Amsterdam, 2014.

[12] H. K. D. H. Bhadeshia, Bulletin of the polish academy of sciences. Technical sciences.58 (2010) 255-265.

[13] C. Garcıa de Andrés, F. G. Caballero, C. Capdevila, L. F. Alvarez, Mater. Charact. 48 (2002)101-111.

[14] H. Ghasemi-Nanesa, M. Jahazi, Mater. Sci. Eng. A. 598 (2014) 413-419.

[15] D. Bombac, M. Fazarinc, A. Saha Podder, G. Kugler, JMEPEG. 22 (2013) 742-747.

[16] J. W. Christian, Theory of phase transformation in metals and alloys, 2nd ed,. Pergamon Press, Oxford, 1975.

[17] H. K. D. H. Bhadeshia, Prog. Mater. Sci. 29 (1985) 321-386.

[18] J. D. Watson, P. G. McDougall, Acta Metall. 21 (1973) 961-973.

[19] S. S. Babu, H. K. D. H. Bhadeshia, Mater. Sci. Eng. A. 156 (1992) 1-9.

[20] S. S. Babu, H. K. D. H. Bhadeshia, Mater .Trans. 32, JIM (1991) 679-688.

[21] I. Madariaga, I. Gutiérrez, C. Garcia-de Andrés, C. Capdevila: Scripta Mater. 41 (1999) 229235. 


\section{Figures captions}

Fig.1. Influence of cooling rate on the resulted microstructure (a: optical image) and (b to d: SEM micrographs): cooling rate $0.5 \mathrm{~K} \cdot \mathrm{s}^{-1}$ (e to f): cooling rate $50 \mathrm{~K} \cdot \mathrm{s}^{-1}$, observation of carbides (C), allotriomorphic ferrite (ATF), Widmanstätten ferrite (WF), Acicular ferrite (AF), and Bainite (B) during low cooling rate (a-d) and observation of $\mathrm{C}$ and martensite (M) for high cooling rate conditions (e: optical image, f: SEM micorgraph).

Fig.2. (a) and (b) Bright and dark field TEM micrograph showing bainite plate consisted of much smaller subunits after cooling at a rate of $0.5 \mathrm{~K}^{-1}{ }^{-1}$, (c) and (d): Bright and dark field TEM micrographs from martensitic microstructure showing mixed laths and plates of martensite after cooling at a rate of $50 \mathrm{~K} . \mathrm{s}^{-1}$.

Fig.3. (a) Dilatometric curve of alloy during cooling at rate of $0.5 \mathrm{~K} . \mathrm{s}^{-1}$ with determination of different phase transformation ranges (b) Changes in dilatational strain (balck curve) between $400 \mathrm{~K}$ and $600 \mathrm{~K}$ from part (a) and its temperature derivative $\left(\mathrm{d}\left(\Delta \mathrm{L} / \mathrm{L}_{0}\right) / \mathrm{dT}\right.$ (green curve) revealing $\mathrm{AF}$ formation region before start of bainitic transformation. (Symbol description: (CP): Carbides precipitation, ( ATF): allotriomorphic ferrite, (WF): Widmanstätten ferrite, (AF): Acicular ferrite, and (B): Bainite)

Fig.4. (a) Dilatometric curve of alloy during cooling at rate of $50 \mathrm{~K} \cdot \mathrm{s}^{-1}$ depicting the start of martensitic transformation, (b) Changes in dilatational strain (balck curve) between $420 \mathrm{~K}$ and $580 \mathrm{~K}$ from part (a) and its temperature derivative $\left(\mathrm{d}\left(\Delta \mathrm{L} / \mathrm{L}_{0}\right) / \mathrm{dT}\right.$ (green curve) to determine $\mathrm{M}_{\mathrm{s} 1}(\mathrm{~T})$ and $\mathrm{M}_{\mathrm{s} 2}(\mathrm{~T})$. (Symbol M denotes martensite)

Fig.5. Effect of two applied cooling rates on the volume fraction of carbides with average area below $1 \mu \mathrm{m}^{2}$ in the microstructure after (a): cooling rate $0.5 \mathrm{~K} \cdot \mathrm{s}^{-1}$ and (b): cooling rate $50 \mathrm{~K} \cdot \mathrm{s}^{-1}$. 


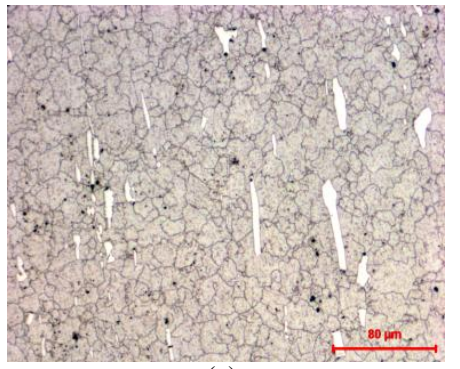

(a)

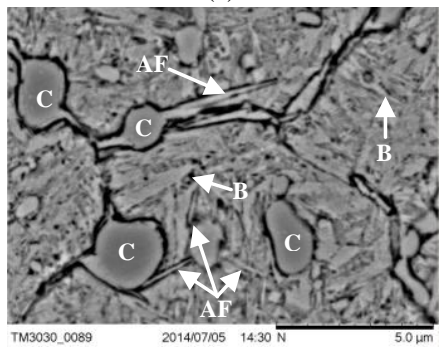

(d)

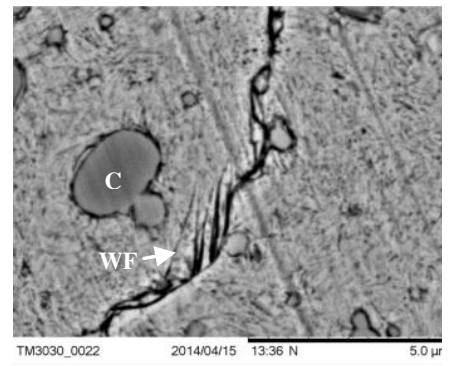

(b)

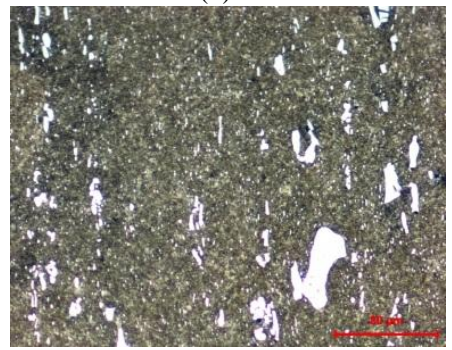

(e)

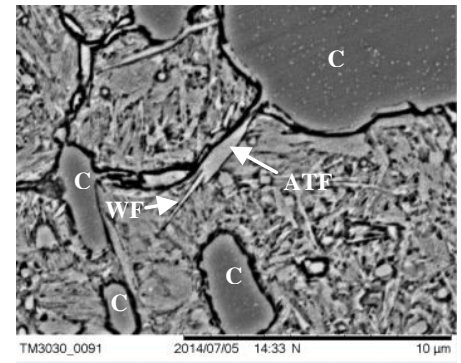

(c)

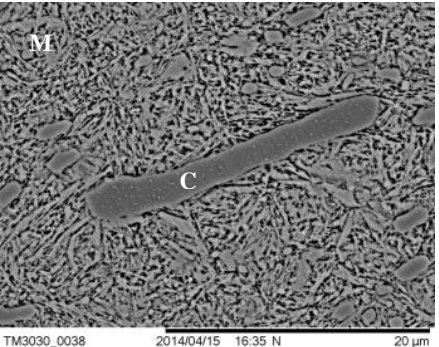

(f)

Fig.1. Influence of cooling rate on the resulted microstcuture (a: optical image) and (b to d: SEM micrographs): cooling rate $0.5 \mathrm{~K} . \mathrm{s}^{-1}$ (e to f): cooling rate $50 \mathrm{~K} . \mathrm{s}^{-1}$, observation of carbides (C), allotriomorphic ferrite (ATF), Widmanstätten ferrite (WF), Acicular ferrite (AF), and Bainite (B) during low cooling rate (a-d) and observation of $\mathrm{C}$ and martensite $(\mathrm{M})$ for high cooling rate conditions (e: optical image, f: SEM micorgraph). 


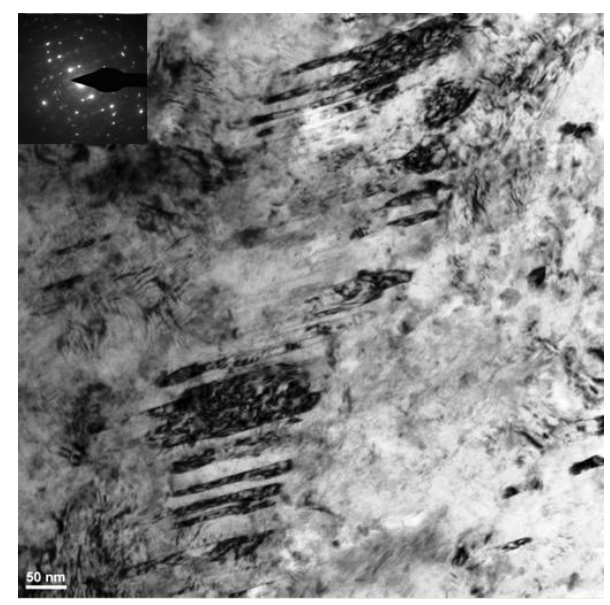

(a)

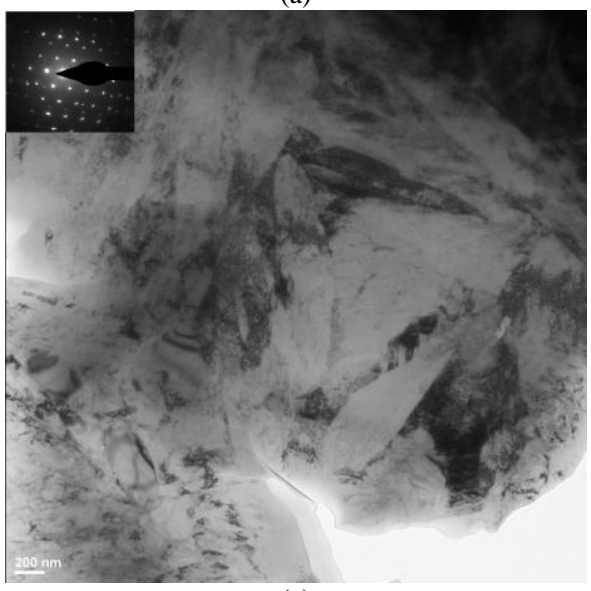

(c)

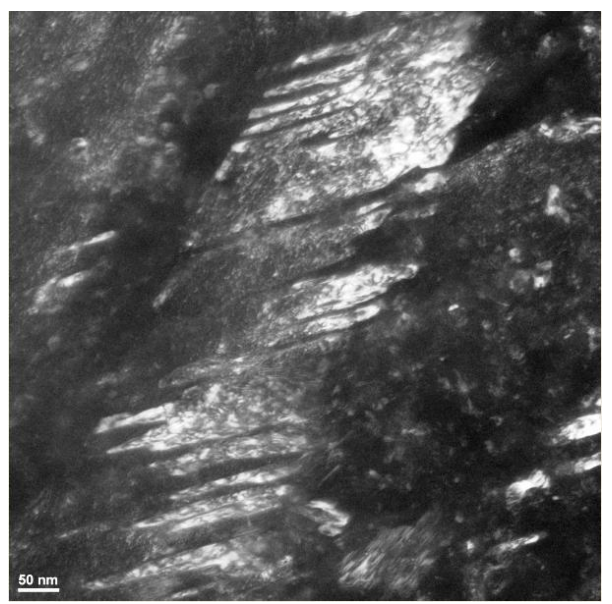

(b)

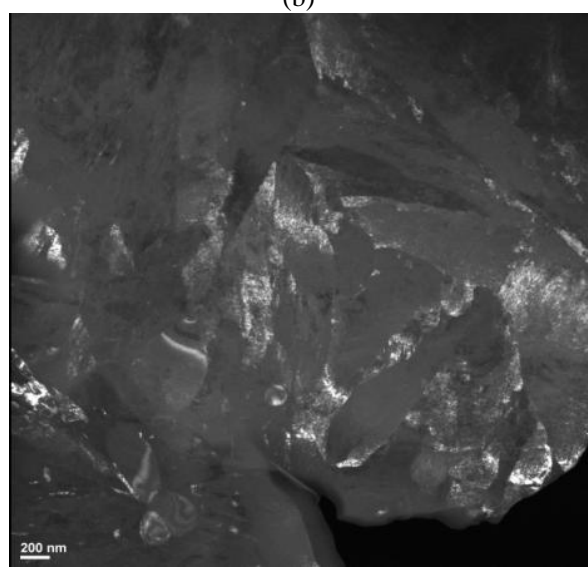

(d)

Fig.2. (a) and (b) Bright and dark field TEM micrograph showing bainite plate consisted of much smaller subunits after cooling at a rate of $0.5 \mathrm{~K}^{-1} \mathrm{~s}^{-1}$, (c) and (d): Bright and dark field TEM micrographs from martensitic microstructure showing mixed laths and plates of martensite after cooling at a rate of $50 \mathrm{~K} \cdot \mathrm{s}^{-1}$. 

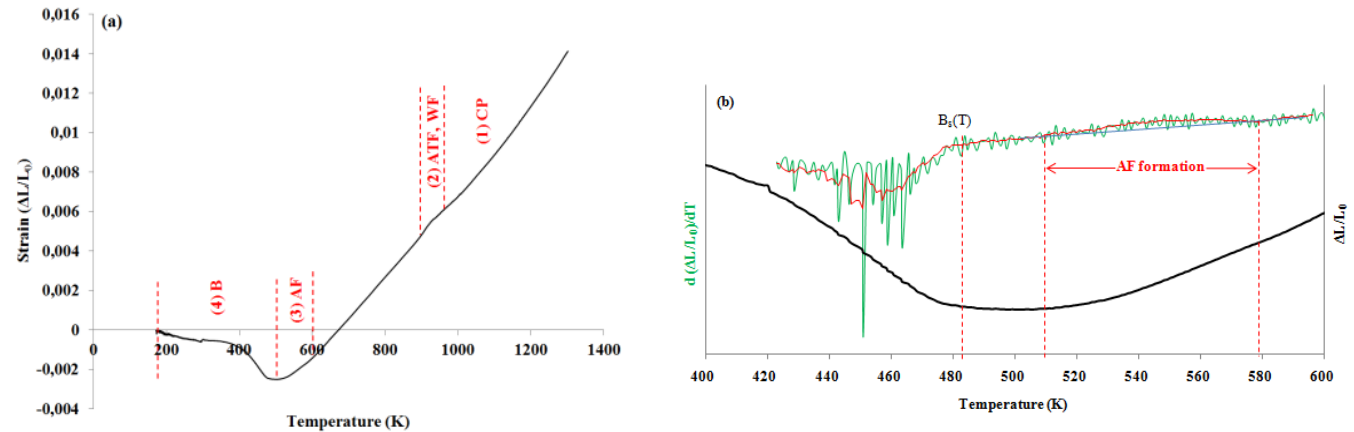

Fig.3. (a) Dilatometric curve of alloy during cooling at rate of $0.5 \mathrm{~K} . \mathrm{s}^{-1}$ with determination of different phase transformation ranges (b) Changes in dilatational strain (balck curve) between $400 \mathrm{~K}$ and $600 \mathrm{~K}$ from part (a) and its temperature derivative $\left(\mathrm{d}\left(\Delta \mathrm{L} / \mathrm{L}_{0}\right) / \mathrm{dT}\right.$ (green curve) revealing $\mathrm{AF}$ formation region before start of bainitic transformation. (Symbol description: (CP): Carbides precipitation, ( ATF): allotriomorphic ferrite, (WF): Widmanstätten ferrite, (AF): Acicular ferrite, and (B): Bainite) 

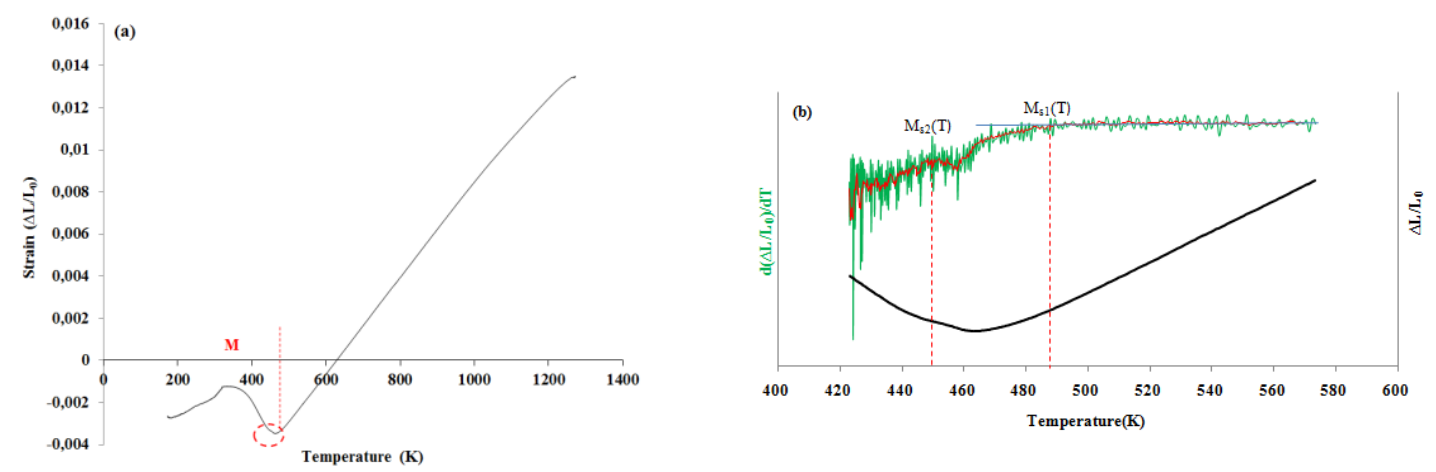

Fig.4. (a) Dilatometric curve of alloy during cooling at rate of $50 \mathrm{~K} \cdot \mathrm{s}^{-1}$ depicting the start of martensitic transformation, (b) Changes in dilatational strain (balck curve) between $420 \mathrm{~K}$ and $580 \mathrm{~K}$ from part (a) and its temperature derivative (d $\left(\Delta \mathrm{L} / \mathrm{L}_{0}\right) / \mathrm{dT}$ (green curve) to determine $\mathrm{M}_{\mathrm{s} 1}(\mathrm{~T})$ and $\mathrm{M}_{\mathrm{s} 2}(\mathrm{~T})$. (Symbol $\mathrm{M}$ denotes martensite) 


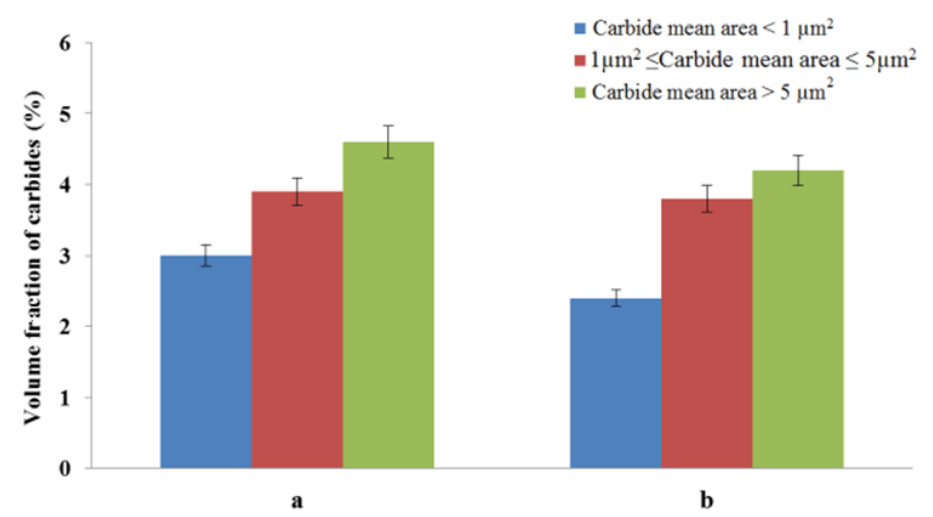

Fig.5. Effect of two applied cooling rates on the volume fraction of carbides with average area below 1 $\mu \mathrm{m}^{2}$ in the microstructure after (a): cooling rate $0.5 \mathrm{~K}^{-\mathrm{s}^{-1}}$ and (b): cooling rate $50 \mathrm{~K} . \mathrm{s}^{-1}$. 